\title{
2. Have civil society organizations' political empowerment programmes contributed to a deepening of democracy in Kenya?
}

\author{
CELESTINE NYAMU MUSEMBI ${ }^{1}$
}

\section{Introduction}

This chapter evaluates whether the political empowerment programmes undertaken by civil society organizations (CSOs) at the local level have translated into a deepening of democracy in Kenya. It is part of a wider study (Okello, this volume) that has assessed fifteen years of civil society engagement in political reform since multiparty politics began in 1992. It concludes that the record is mixed: CSO political empowerment programmes score high in terms of fostering civic virtue, teaching political skills and nurturing a growing ability and willingness on the part of grassroots communities to check abuses of power at the local level. However, the programmes gain only an average score in terms of their contribution to enhancing the autonomy and sustainability of grassroots associational life, and rate very low on their contribution to an improvement in the quality and equality of representation of interests in local governance.

In Kenya, as in most of sub-Saharan Africa, the early 1990s saw the start of a significant investment of donor resources to support civil society political activism, which translated into the development of a virtually new 'human rights and governance' CSO sector. A survey of non-profit organizations found that, up until 1980, only one organization had described itself as doing 'civic and advocacy' work. Over the next ten years, under a repressive single-party system, no organization would describe itself in these terms. However, between 1991 and 2001, six organizations described themselves thus. This figure understates the exponential growth of organizations in the sector during this period, as many new organizations did not seek formal registration in their own right, preferring to take cover as a programme within an existing organization (Institute for Develoment Studies, 2007: 6; Mutunga, 1999).

At the national level, political activists - along with other actors in broader civil society, including religious organizations and professional societies - have taken part in articulating a macro-political reform 
agenda. This alliance of forces was key in challenging the one-party state. CSOs have also contributed to the strengthening of democracy at the national level (Okello, this volume). At the local level, a significant number of organizations in this CSO sub-sector have also invested in the grassroots political empowerment initiatives that are the focus of this chapter. ${ }^{2}$

\section{Framing research questions on 'deepening democracy': how do we know what we are looking for?}

In order to examine these grassroots political empowerment initiatives properly, we must make explicit what we consider to be indicators of deepened democracy. This is an inescapably contextual and subjective (even normative) exercise. We developed evaluative questions, guided by the literature on civil associations and their contribution to the process of democratization. Archon Fung usefully groups into six categories the types of contribution that civil associations are said to make towards enhancing democracy (Fung, 2003: 515). He bases the categories on a selection of the arguments from the literature on associations and democracy:

1 Intrinsic value: that the very existence of associative life enhances democracy by virtue of expressing the freedom of association.

2 Fostering civic virtue and teaching political skills.

3 Offering resistance to power and checking government.

4 Improving the quality and equality of representation of interests.

5 Facilitating public deliberation.

6 Creating opportunities for citizens and groups to participate directly in governance.

Using Fung's list as a point of reference, we generated the following evaluative questions for the study:

1 Have CSO-initiated political empowerment programmes enriched associational life at the grassroots level?

2 Have CSO initiatives fostered civic virtue and taught political skills at the grassroots level?

3 Have CSO initiatives played a role in checking abuse of power at the local level?

4 Has CSO intervention improved the quality and equality of representation of interests in local governance?

5 Have CSOs played a role in facilitating public deliberation and creating opportunities for direct participation in governance? 


\section{Methodology: sample design, sampling procedures and site selection}

The study surveyed 500 purposively selected respondents, half of whom had received training through CSO-initiated grassroots political empowerment programmes and half of whom had not. ${ }^{3}$ Identifying trained respondents proved to be less straightforward than we had hoped. First, we identified organizations working at the grassroots level. We first consulted the Paralegal Support Network (PASUNE), formed belatedly in 2003 to bring some coordination to the myriad initiatives in community-based paralegal training conducted by CSOs at the grassroots level between 1992 and 1999. From PASUNE we obtained a partial database of the community paralegal workers trained by each of the network's members.

We then approached member organizations individually to supplement this information, as well as organizations that were not members of PASUNE but that we knew from previous research (NyamuMusembi and Musyoki, 2004) to be involved in grassroots political empowerment work. We also asked the trained respondents of grassroots political empowerment programmes whether they knew of other people who had received similar training.

In selecting the non-trained respondents, we targeted people who could be considered 'peers' of the trained respondents in terms of age, gender, income and educational level. For the sake of balance, in each district we drew the non-trained respondents from the same geographical locality and situation as the trained respondents. If we interviewed a school teacher who was trained as a community paralegal worker, for example, we would find another school teacher who was not. This enabled us to minimize the significance of any differentiating factors (gender, age, income and level of education) other than the key variable, namely having been trained through a CSO-initiated political empowerment programme.

From the information available to us, we established that there had been CSO-led political empowerment initiatives in twenty-five districts; ${ }^{4}$ we drew our sample from ten of these. In selecting the study districts, we took into account the need to represent as many of the country's regions as possible, organizational diversity (so as not to concentrate excessively on the initiatives of one organization) and balance in approaches to political empowerment. ${ }^{5}$

Data collection was by means of a semi-structured questionnaire. In addition to the survey, we also conducted key informant interviews with leaders of selected CSOs, and we examined their programme records. 